\title{
Biological activity and safety evaluation of monoterpenes against the peach aphid (Myzus persicae Sulzer) (Hemiptera: Aphididae)
}

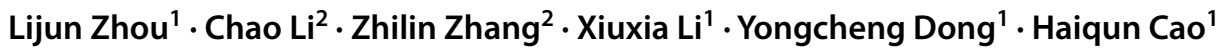

Received: 25 August 2020 / Accepted: 28 January 2021 / Published online: 16 February 2021

(c) The Author(s) 2021

\begin{abstract}
The green peach aphid, Myzus persicae (Sulzer) (Hemiptera: Aphididae), is an economically important cosmopolitan crop pest. Essential oils (EOs) are complex mixtures of secondary metabolites that exhibit a wide range of biological activities, including antioxidant, antimicrobial and anti-inflammatory activities. Monoterpenes, as the major constituents of EOs, are well known for having a range of biological activities. In this study, 9 monoterpenes were screened for fumigant toxicity against M. persicae, and the safety of monoterpenes to natural enemies was evaluated. The results of the bioassays indicated that 9 monoterpenes showed promising fumigant toxicity against $M$. persicae. Carvacrol was the most toxic compound based on the $\mathrm{LC}_{50}$ value, which was $1.566 \mathrm{mg} / \mathrm{L}$, followed by bornyl acetate, terpinolene, and terpinyl acetate, which had higher toxicities towards aphids, with $\mathrm{LC}_{50}$ values of $2.648 \mathrm{mg} / \mathrm{L}, 2.759 \mathrm{mg} / \mathrm{L}$, and $2.832 \mathrm{mg} / \mathrm{L}$, respectively. In addition, the safety evaluation assays of carvacrol against Harmonia axyridis (Pallas) (Coleoptera: Coccinellidae) larvae $\left(\mathrm{LC}_{50}=43.851 \mathrm{mg} / \mathrm{L}\right.$ ) did not affect nontarget invertebrates at concentrations that effectively controlled aphids. Carvacrol was safer than chlorpyrifos to natural enemy $H$. axyridis larvae (toxicity ratio $=28.00>2.93$ ). These results identified several high-activity monoterpenes that can be used against this pest in greenhouses as botanical insecticides.
\end{abstract}

Keywords Monoterpenes $\cdot$ Myzus persicae $\cdot$ Carvacrol $\cdot$ Harmonia axyridiss $\cdot$ Toxicity ratio

\section{Introduction}

The green peach aphid, Myzus persicae (Sulzer) (Hemiptera: Aphididae), is a cosmopolitan and very economically important crop pest that is highly polyphagous (MachadoAssefh and Alvarez 2016). M. persicae is remarkably adept at destroying the quality of economically important crops of agricultural, horticultural and greenhouse crops (Sial 2019); this pest has broad host ranges and transmits many plant viruses (Tang et al. 2015; Zeng et al. 2016). The host plants

Haiqun Cao

caohq@ahau.edu.cn

1 Key Laboratory of Biology and Sustainable Management of Plant Diseases and Pests of Anhui Higher Education Institutes, College of Plant Protection, Anhui Agricultural University, Hefei 230036, PR China

2 Hubei Key Laboratory of Quality Control of Characteristic Fruits and Vegetables, College of Life Science and Technology, Hubei Engineering University, Xiaogan 432000, PR China include 400 species in 40 different plant families, such as Solanaceae and Asteraceae. In addition, M. persicae feeds on the vascular bundles of plants, including potatoes, cabbages, and peppers, and transmits 100 plant viruses, (Kuhar and Doughty 2010; Tang et al. 2015; Zeng et al. 2016).

Currently, insecticides have become one of the main measures for controlling aphids in field crops (Charaabi et al. 2018). The chemical insecticides included organophosphates, carbamates, pyrethroids, and neonicotinoids (Walgenbach and Schoof 2011; Zeng et al. 2016). In China, an increasing number of insecticides have been restricted because of their environmental impacts. Aphids have developed strong resistance to many different types of chemical insecticides because of the application of insecticides (Elbert et al. 2008; Sial et al. 2018). Currently, an important challenge in developing insecticides is finding novel and effective compounds; this effort is faced with the problems of insecticide resistance and impacts on human health, and the environment (Benelli et al. 2018; Xiao and Wu 2019). Environmentally friendly insecticides were developed for 
pest control purposes to reduce environmental pollution and food safety problems (Cai et al. 2020).

Essential oils (EOs) are a complex of secondary metabolite mixtures (including terpenes, phenolic compounds, and alcohol) that exhibit a wide range of biological activities, including antioxidant, antimicrobial and anti-inflammatory activities (Hanen et al. 2020). Because these complexes have low toxicity levels to vertebrates and nontarget aquatic invertebrates and are fully biodegradable, multifunctional, efficient and environmentally safe (Pavela and Benelli 2016; Pavela et al. 2019), the insecticidal properties of EOs and plant extracts are being studied as new alternative pesticides. A number of plants have been screened as potential natural repellent and insecticide compounds (Singhet al. 2006). For example, Kumar et al. (2011) investigated the repellent, larvicidal and pupicidal activities of the EOs of six plant species for the control of different stages of the housefly lifecycle, and Mentha piperita (Linn.) oil has been indicated to be the best repellent, larvicidal and pupicidal agent. The EOs of Pimpinella anisum (L.) fruits have been reported to show strong toxicity on Culex quinquefasciatus (Say) and did not have any effect on Daphnia at short exposure times or low concentrations (Pavela et al. 2014).

Monoterpenes, which are the major components of EOs, are well known for a range of biological activities, such as herbicidal, antifungal and insecticidal activities (Zhang et al. 2016a, b, 2017, 2018; Gouda et al. 2016). In this study, we were interested in appraising the insecticidal properties of 9 monoterpenes, including bornyl acetate, carvacrol, citronellyl acetate, eugenol, geranyl acetate, linalyl acetate, neryl acetate, terpinolene and terpinyl acetate. These monoterpenes have been reported to possess superior insecticidal activity against Reticulitermes chinensis Snyder, Musca domestica L., Plutella xylostella L. (Xie et al. 2014; Zhang et al. 2017; Cai et al. 2020). However, no studies have been conducted to evaluate the insecticidal activities of monoterpenes against vegetable pests in greenhouses. Therefore, we assessed the toxicities of 9 monoterpenes against $M$. persicar. Our results identified several high-activity monoterpenes that can be used against this pest in greenhouses as botanical insecticides. Furthermore, the potential ecotoxicological consequences arising from the high-activity monoterpene were investigated by testing them on the natural enemy of aphids, Harmonia axyridis (Pallas) (Coleoptera: Coccinellidae).

\section{Materials and methods}

\section{Insect tested and rearing of conditions}

The green peach aphid (M. persicae) used in this study was obtained from the laboratory of China Agricultural University,
Beijing, China. The aphids were a susceptible laboratory strain that had not had exposure to any insecticides since September 2008 (Tang et al. 2015). M. persicae was reared on cabbage (Brassica oleracea (L.)) seedlings and maintained at $23 \pm 1{ }^{\circ} \mathrm{C}$ in $65-75 \%$ relative humidity $(\mathrm{RH})$ and under a photoperiod of 16:8 (L: D) h.

H. axyridis eggs were purchased from Jiyuan Baiyun Industry Co., Ltd. Following egg eclosion, the larvae were placed on plastic Petri dishes and provided with aphids daily. The larvae were maintained at $25 \pm 2{ }^{\circ} \mathrm{C}$ and $75 \% \pm 5 \%$ relative humidity and under a 16 -h photoperiod.

\section{Chemicals}

The 7 from 9 experimental monoterpenes compounds, included bornyl acetate, carvacro, citronellyl acetate, geranyl acetate, linalyl acetate, neryl acetate and terpinyl acetate, were purchased from Tokyo Chemical Industry Co., Ltd. (Shanghai, China). In additional, eugenol and terpinolene were sourced from Sigma-Aldrich Co., Ltd. (Poole, UK). Chlorpyrifos was used as control chemical pesticide, and purchased from Hengdong Chemical Industry Co., Ltd. (Shandong, China). All chemical structures and purity metrics are provided in Table 1 . The compounds were stored at $-20^{\circ} \mathrm{C}$ until use.

\section{Fumigation bioassay}

The insecticidal toxicity of 10 volatile compounds to adult apterous aphids was tested according to the method of Zhang et al. (2016b) with slight modifications. Filter papers $(1 \mathrm{~cm}$ diameter) were soaked in a certain amount of compounds or chlorpyrifos (positive control), and an untreated filter paper (containing acetone; control) was used as a blank control. All were placed in $500 \mathrm{~mL}$ glass jars. In every test system, approximately 30 individuals of $M$. persicae were evaluated. The concentration for each test is shown in Fig. 1. For the liquid monoterpenes, the compounds were directly taken at a certain amount for the experimental study. Chlorpyrifos was configured in a series of concentrations with acetone, and the final volume per treatment was $15 \mu \mathrm{L}$. The aphid mortalities were noted after $24 \mathrm{~h}$ according to agricultural industry standard of the people's Republic of China (NY/T 1154.3-2006), and all tests were kept at $23 \pm 1{ }^{\circ} \mathrm{C}$, with $65-75 \% \mathrm{RH}$. The aphids were considered dead only when they were probed with a soft paintbrush and did not display any movement, even of their legs (Moores et al. 1996). Three replicates of each control and treatment were tested.

Third instar larvae of $H$. axyridis were used to test the toxicity of the most toxic compound. The concentration and application method were utilized in the fumigation assay. The mortalities of $H$. axyridis larvae were noted after $24 \mathrm{~h}$. The concentration used in each test is shown in Fig. 2. The larvae of $H$. axyridis were provided aphids as food during each fumigation assay. 
Table 1 The 10 compounds for fumigation bioassay

\begin{tabular}{|c|c|c|c|c|}
\hline Code & Compounds & Purity (\%) & Structure & Source \\
\hline 1 & Bornyl Acetate & 70 & & TCI \\
\hline 2 & Carvacrol & 95 & & TCI \\
\hline 3 & Citronellyl Acetate & 95 & & TCI \\
\hline 4 & Eugenol & 98 & & Sigma-Aldrich \\
\hline 5 & Geramyl Acetate & 70 & & TCI \\
\hline 6 & Linalyl Acetate & 95 & & TCI \\
\hline 7 & Neryl Acetate & 95 & & TCI \\
\hline 8 & Terpinolene & 85 & & Sigma-Aldrich \\
\hline 9 & Terpinyl Acetate & 78 & & TCI \\
\hline 10 & Chlorpyrifos & 80 & & $\mathrm{HCI}$ \\
\hline
\end{tabular}

\section{Data analysis}

Statistical analyses were conducted with POLOPlus 2.0 (LeOra Software, Petaluma, CA, USA). The criterion of non-overlapping $95 \%$ confidence intervals (CIs) was used to consider significant differences in the $\mathrm{LC}_{50} \mathrm{~s}$ and $\mathrm{LC}_{90} \mathrm{~s}$.

To evaluate the safety of the insecticides to the natural enemy, the ratio of the $\mathrm{LC}_{50}$ of insecticide to natural enemy to the $\mathrm{LC}_{50}$ of insecticide to insect pest was determined (Wang and Shen 2002). The calculation formula is as follows:

Toxicity $=\frac{\mathrm{LC}_{50} \text { of insecticide to natural enemy }}{\mathrm{LC}_{50} \text { of insecticide to insect pest }}$

\section{Results}

The toxicities of 9 pure commercial monoterpenes, including 1 hydrocarbon, 2 aldehydes, and 6 acetate esters, were determined against adults of M. persicae (Fig. 1).
Carvacrol and terpinolene had greater than $80 \%$ mortality against aphids at concentrations of $5 \mathrm{mg} / \mathrm{L}$ (Fig. 1b, h). The mortality of geranyl acetate and linalyl acetate was between 20 and $40 \%$ at a concentration of $5 \mathrm{mg} / \mathrm{L}$ (Fig. 1c, e). Weak toxicity against aphids was shown by neryl acetate, with $80 \%$ mortality against aphids at concentrations greater than $40 \mathrm{mg} / \mathrm{L}$ (Fig. 1g). The $\mathrm{LC}_{50}$ values of the 9 monoterpenes against aphids were determined and shown in Table 2. The insecticidal activity of carvacrol, bornyl acetate, terpinolene, and terpinyl acetate had higher toxicities towards aphids, with $\mathrm{LC}_{50}$ values of $1.566 \mathrm{mg} / \mathrm{L}, 2.648 \mathrm{mg} / \mathrm{L}, 2.759 \mathrm{mg} / \mathrm{L}$, and $2.832 \mathrm{mg} / \mathrm{L}$, respectively. With the exception of the positive control insecticides, all other tested compounds had $\mathrm{LC}_{50}$ estimates ranging from $4.03 \mathrm{mg} / \mathrm{L}$ to $9.64 \mathrm{mg} / \mathrm{L}$. The positive control chlorpyrifos showed considerably higher toxicity than any of the monoterpene compounds $\left(\mathrm{LC}_{50}=0.028 \mathrm{mg} / \mathrm{L}\right)$.

The effects of carvacrol and chlorpyrifos on the natural enemy were evaluated, and the $\mathrm{LC}_{50}$ values of these 

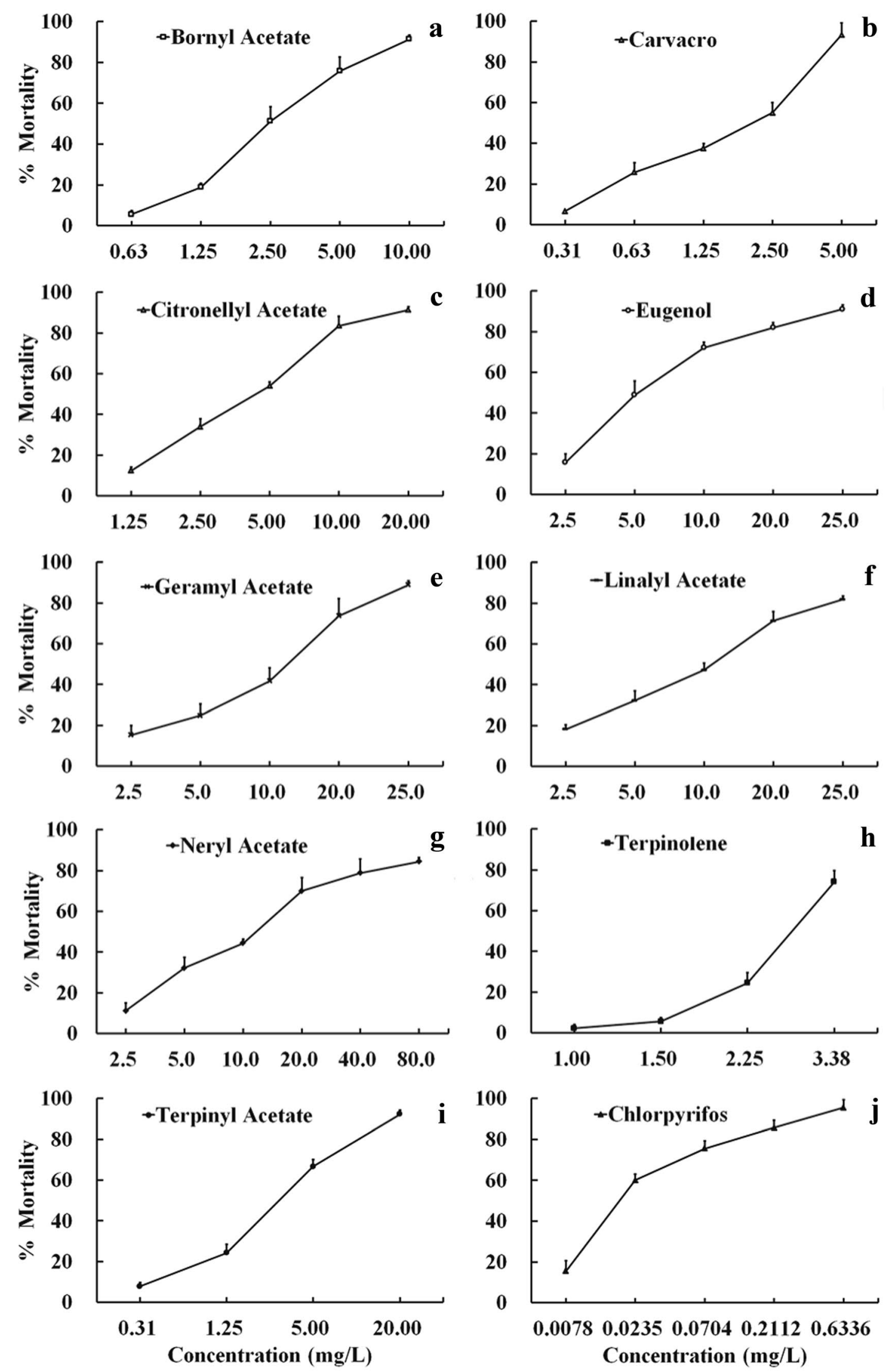
४Fig. 1 Toxicity of 10 compounds against M. persicae. a Bornyl Acetate, b Carvacro, c Citronellyl Acetate, d Eugenol, e Geramyl Acetate, $\mathbf{f}$ Linalyl Acetate, $\mathbf{g}$ Neryl Acetate, $\mathbf{h}$ Terpinolene, i Terpinyl Acetate, and $\mathbf{j}$ Chlorpyrifos, respectively

Fig. 2 Safety evaluation assays of two compounds against H. axyridis. a Carvacro, and b Chlorpyrifos, respectively

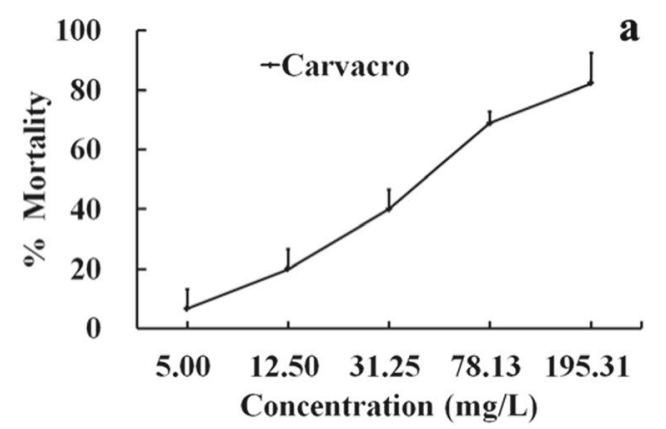

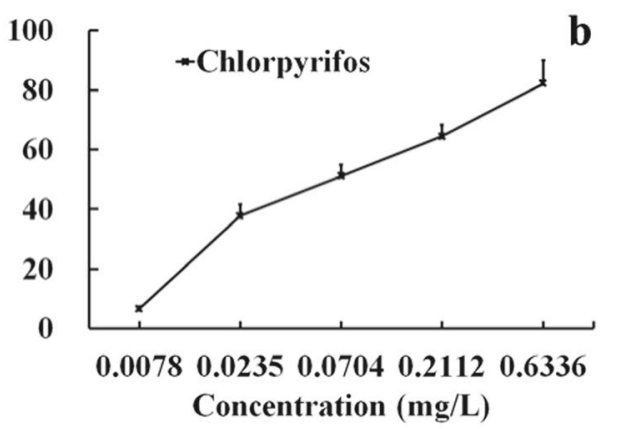

compounds against $H$. axyridis larvae are shown in Table 3. According to the toxicity ratio, carvacrol was safer than chlorpyrifos to the larvae of the natural enemy $H$. axyridis (toxicity ratio $=28.00>2.93$ ).

\section{Discussion}

Our study showed that the 9 monoterpenes tested had varying degrees of insecticidal activity against aphids, and the mortality from the monoterpenes generally increased with increasing doses. Among the tested compounds, carvacrol, bornyl acetate, terpinolene, and terpinyl acetate possessed relatively strong toxicities against $M$. persicae. According to the toxicity ratio, carvacrol was safer than chlorpyrifos to $H$. axyridis larvae.

Some monoterpenes in the EOs and plant extracts have been affirmed to possess very strong toxicity against the various insect species in several studies. Park et al. (2017) reported that carvacrol and thymol from Thymus vulgaris $\mathrm{L}$. showed the strongest activity against Pochazia shantungensis (Chou \& Lu) adults and nymphs. The EOs from Cuminum cyminum L. and Pimpinella anisum L. were toxic to larvae of C. quinquefasciatus and Spodoptera littoralis (Bosid) but did not affect nontarget invertebrates (Benelli et al. 2018). In addition, Zhang et al. (2016b; 2017) showed that thymol, carvacrol, (+)-pulegone, citral, ( \pm )-citronellal, and cuminaldehyde had strong fumigation activity against M. domestica and Drosophila melanogaster Meig. In this respect, we assessed the toxicities of 9 monoterpenes against aphids in the laboratory, and the results showed that monoterpenes were also more effective against $M$. persicae and could be used successfully as a control agent for aphids.

In this study, carvacrol possessed relatively strong toxicity against aphids, and the $\mathrm{LC}_{50}$ value against M. persicae was $1.566 \mathrm{mg} / \mathrm{L}$. Carvacrol is a phenolic monoterpenoid that is found in the essential oils of some plants, such as Origanum vulgare L. and T. vulgaris (Sharifi-Rad et al. 2017). Xie et al. (2019) reported that the percentage inhibition rate of carvacrol against pupae of $M$. domestica was $29.5 \%\left(0.025 \mu \mathrm{L} / \mathrm{cm}^{2}\right)$ according to a contact toxicity assay and $81.8 \%(1.25 \mu \mathrm{L} / \mathrm{L})$ according to a fumigation assay. Castilhos et al. (2017) showed that carvacrol was more acutely toxic than the other terpenoids screened, but it had less toxicity than natural pyrethrins. Furthermore, carvacrol has a wide range of bioactivities
Table $2 \mathrm{LC}_{50}$ and $\mathrm{LC}_{90}$ values $(\mathrm{mg} / \mathrm{L})$ of 10 compounds against $M$. persicae adults over $24 \mathrm{~h}$

\begin{tabular}{lcccr}
\hline Compounds & $\mathrm{LC}_{50} /(\mathrm{mg} / \mathrm{L})(95 \% \mathrm{CL})$ & $\mathrm{LC}_{90} /(\mathrm{mg} / \mathrm{L})(95 \% \mathrm{CL})$ & Slope $\pm \mathrm{SE}$ & $\chi^{2}(\mathrm{df})$ \\
\hline Bornyl Acetate & $2.648(2.325-3.018)$ & $8.611(7.054-11.132)$ & $2.503 \pm 0.196$ & $4.492(13)$ \\
Carvacro & $1.566(1.309-1.896)$ & $6.483(4.742-10.176)$ & $2.077 \pm 0.180$ & $15.676(13)$ \\
Citronellyl Acetate & $4.029(3.492-4.626)$ & $14.481(11.673-19.271)$ & $2.307 \pm 0.199$ & $2.650(13)$ \\
Eugenol & $6.058(5.136-7.011)$ & $24.049(19.475-31.851)$ & $2.140 \pm 0.193$ & $7.503(13)$ \\
Geramyl Acetate & $9.635(8.148-11.388)$ & $37.723(28.569-56.295)$ & $2.162 \pm 0.193$ & $15.013(13)$ \\
Linalyl Acetate & $9.282(7.822-11.006)$ & $51.253(36.945-82.543)$ & $1.727 \pm 0.181$ & $4.470(13)$ \\
Neryl Acetate & $13.166(10.479-16.464)$ & $103.395(69.758-181.761)$ & $1.432 \pm 0.125$ & $19.164(16)$ \\
Terpinolene & $2.751(2.514-3.076)$ & $4.594(3.923-5.913)$ & $5.757 \pm 0.587$ & $12.929(10)$ \\
Terpinyl Acetate & $2.832(2.263$ to 3.555) & $17.317(12.321-27.150)$ & $1.630 \pm 0.140$ & $2.854(10)$ \\
Chlorpyrifos & $0.028(0.019-0.038)$ & $0.234(0.152-0.447)$ & $1.379 \pm 0.127$ & $20.679(13)$ \\
\hline
\end{tabular}


Table 3 Safety evaluation of carvacrol and chlorpyrifos for H. axyridis

\begin{tabular}{lcllc}
\hline compounds & $\mathrm{LC}_{50} /(\mathrm{mg} / \mathrm{L})(95 \% \mathrm{CL})$ & $\mathrm{Slope} \pm \mathrm{SE}$ & $\chi^{2}(\mathrm{df})$ & Toxicity ratio \\
\hline Carvacro & $43.851(33.183-59.172)$ & $1.555 \pm 0.190$ & $6.414(13)$ & 28.00 \\
Chlorpyrifos & $0.082(0.056-0.121)$ & $1.112 \pm 0.152$ & $7.661(13)$ & 2.93 \\
\hline
\end{tabular}

that are putatively useful for insecticide, antimicrobial, and antioxidant activities (Sharifi-Rad et al. 2017; Cai et al. 2020). Kordali et al. (2008) certified that the EOs isolated from Origanum acutidens (Hand.-Mazz.) had antifungal, phytotoxic and insecticidal activities; furthermore, the major component, carvacrol, had the potential to be used as fungicide, herbicide and insecticide. Our previous studies have shown that carvacrol possesses good antifungal activities against fungi, such as Trametes hirsute (Wulfen), Schizphylhls commune (Fr.), Pycnoporus sanguineus (L.), Rhizopus stolonifer and Absidia coerulea (Zhang et al. 2016b; Zhou et al. 2019). Together, these studies proved that carvacrol can be used for the development of antifungal and fungicidal agents and insecticidal agents for controlling agricultural pests and diseases.

In addition, the insecticidal activities of bornyl acetate were generally more toxic than terpinolene, terpinyl acetate, citronellyl acetate, eugenol, linalyl acetate, geranyl acetate, and neryl acetate. Similarly, bornyl acetate has been found to be more effective than other monoterpenes in insecticidal activity against $R$. chinensis (Xie et al. 2014). Bornyl acetate is one major constituent of Valeriana officinalis (L.), and the EOs extracted from the roots of Valeriana officinalis showed promising fumigant and contact toxicity against Liposcelis bostrychophila (Booklouse) $\left(2.8 \mathrm{mg} / \mathrm{L}\right.$ air and $\mathrm{LD}_{50}=50.9 \mu \mathrm{g} /$ $\mathrm{cm}^{2}$, respectively). Furthermore, bornyl acetate also exhibited strong fumigant and contact toxicity against $L$. bostrychophila $\left(\mathrm{LC}_{50}=1.1,10.1 \mathrm{mg} / \mathrm{L}\right.$ air and $\left.\mathrm{LD}_{50}=32.9,701.3 \mu \mathrm{g} / \mathrm{cm}^{2}\right)$ (Feng et al. 2019). Moreover, bornyl acetate, as a repellent of Aedes aegypti L., was active at $0.28 \mathrm{mg} / \mathrm{cm}^{2}$ and higher (Hwang et al. 1985). Early research also found that bornyl acetate possessed the strongest activity against fungi, and the effect was correlated most strongly with the content of bornyl acetate and other monoterpenes (Pellegrini et al. 2017). This study highlighted the insecticidal, antifungal and fungicidal potential of bornyl acetate, which has been noted as a natural botanical agent for insecticide and bacteriostasis.

To evaluate the safety of monoterpenes to natural enemies, safety evaluation assays of carvacrol against $H$. axyridis larvae were conducted in this study, which showed that carvacrol was safer than chlorpyrifos to the natural enemies. Our finding was the same as that of Glavan et al. (2020), who showed that carvacrol caused 5\% mortality in Apis mellifera carnica Pollmann only at the highest concentrations tested. For example, Cai et al. (2020) reported that cuminaldehyde was greater against the adults, larvae, and eggs of $P$. xylostella but did not cause any major damage to their natural enemies $H$. axyridis. Monoterpenes are safe to nontarget aquatic invertebrates at low toxicity levels and are rich sources of botanical pesticides that are easily degradable and exhibit good activity levels against agricultural pests (Copping and Menn 2000).

\section{Conclusions}

In this study, the insecticidal activities of 9 pure monoterpenes against aphids were evaluated. The results of the present study showed that carvacrol, bornyl acetate, terpinolene, and terpinyl acetate have good toxicity against aphids. Furthermore, to evaluate the safety of monoterpenes for natural enemies, the safety of carvacrol against $H$. axyridis larvae was studied, and the results showed that carvacrol was safer than chlorpyrifos for natural enemies. Thus, carvacrol, bornyl acetate, terpinolene, and terpinyl acetate could be developed as potential natural insecticides and be useful as new natural insecticidal agents against aphids.

Acknowledgments This research was supported by National Key R\&D Program of China (No. 2017YFD0600805), and the Central Government Guides Local Science and Technology Development (No. 2019ZYYD045).

\section{Declarations}

Conflict of interest The authors declare that there are no conflicts of interest.

Open Access This article is licensed under a Creative Commons Attribution 4.0 International License, which permits use, sharing, adaptation, distribution and reproduction in any medium or format, as long as you give appropriate credit to the original author(s) and the source, provide a link to the Creative Commons licence, and indicate if changes were made. The images or other third party material in this article are included in the article's Creative Commons licence, unless indicated otherwise in a credit line to the material. If material is not included in the article's Creative Commons licence and your intended use is not permitted by statutory regulation or exceeds the permitted use, you will need to obtain permission directly from the copyright holder. To view a copy of this licence, visit http://creativecommons. org/licenses/by/4.0/.

\section{References}

Benelli G, Pavela R, Petrelli R, Cappellacci L, Canale A, Senthil-Nathan S, Maggi F (2018) Not just popular spices! Essential oils from Cuminum cyminum and Pimpinella anisum are toxic to insect pests 
and vectors without affecting non-target invertebrates. Ind Crop Prod 124:236-243. https://doi.org/10.1016/j.indcrop.2018.07.048

Cai YH, Hu X, Wang P, Xie YJ, Lin ZF, Zhang ZL (2020) Biological activity and safety profile of monoterpenes against Plutella xylostella L. (Lepidoptera: Plutellidae). Environ Sci Pollut Res 27:24889-24901. https://doi.org/10.1007/s11356-020-08751-y

Castilhos RV, Grützmacher AD, Coats JR (2017) Acute toxicity and sublethal effects of terpenoids and essential oils on the predator Chrysoperla externa (Neuroptera: Chrysopidae). Neotrop Entomol 47:311-317. https://doi.org/10.1007/s13744-017-0547-6

Charaabi K, Boukhris-Bouhachem S, Makni M, Denholm I (2018) Occurrence of target-site resistance to neonicotinoids in the aphid Myzus persicae in Tunisia, and its status on different host plants. Pest Manag Sci 74:1297-1301. https://doi.org/10.1002/ ps.4833

Copping LG, Menn JJ (2000) Biopesticides: A review of their action, applications and efficacy. Pest Manag Sci 56:651-676. https:// doi.org/10.1002/1526-4998(200008)56:8\%3c651::AID-PS201\% 3e3.0.CO;2-U

Elbert A, Haas M, Springer B, Thielert W, Nauen R (2008) Applied aspects of neonicotinoid uses in crop protection. Pest Manag Sci 64:1099-1105. https://doi.org/10.1002/ps.1616

Feng YX, Wang Y, Chen ZY, Guo SS, You CY, Du SS (2019) Efficacy of bornyl acetate and camphene from valeriana officinalis essential oil against two storage insects. Environ Sci Pollut Res Int 26:16157-16165. https://doi.org/10.1007/s11356-019-05035-y

Glavan G, Novak S, Božič J, Kokalj AJ (2020) Comparison of sublethal effects of natural acaricides carvacrol and thymolon honeybees. Pestic Biochem Phys 104567. https://doi.org/10.1016/j.pestbp. 2020.104567

Gouda NAA, Saad MMG, Abdelgaleil SAM (2016) PRE and POST Herbicidal Activity of Monoterpenes against Barnyard Grass (Echinochloa crus-galli). Weed Sci 64:191-200. https://doi. org/10.1614/WS-D-15-00045.1

Hanen F, Mariem BJB, Mariem S, Riadh K (2020) Essential oils: A promising eco-friendly food preservative. Food chem 330:127268. https://doi.org/10.1016/j.foodchem.2020.127268

Hwang YS, Wu KH, Kumamoto J, Axelrod H, Mulla MS (1985) Isolation and identification of mosquito repellents in Artemisia vulgaris. $\mathrm{J}$ Chem Ecol 11:1297-1306. https://doi.org/10.1007/BF01024117

Kordali S, Cakir A, Ozer H, Cakmakci R, Kesdek M, Mete E (2008) Antifungal, phytotoxic and insecticidal properties of essential oil isolated from Turkish Origanum acutidens and its three components, carvacrol, thymol and p-cymene. Bioresource Technol 99:8788-8795. https://doi.org/10.1016/j.biortech.2008.04.048

Kuhar TP, Schultz P, Doughty H (2010) Evaluation of soil insecticides for the control of foliar insects in cabbage in Virginia, 2009. Arthropod Manag Tests 35:E3. https://doi. org/10.4182/amt.2011.E65

Kumar P, Mishra S, Satya MA, S (2011) Repellent, larvicidal and pupicidal properties of essential oils and their formulations against the housefly, Musca domestica. Med Vet Entomol 25:302-310. https://doi.org/10.1111/j.1365-2915.2011.00945.x

Machado-Assefh CR, Alvarez AD (2016) Probing behavior of aposymbiotic green peach aphid (Myzus persicae) on susceptible Solanum tuberosum and resistant Solanum stoloniferum plants. Insect Sci 25:127-136. https://doi.org/10.1111/1744-7917.12372

Moores GD, Gao XW, Denholm I, Devonshire AL (1996) Characterisation ofinsensitive acetylcholinesterase in insecticideresistant cotton aphids, Aphis gossypii Glover (Homoptera: Aphididae). Pestic Biochem Phys 56:102-110. https://doi. org/10.1006/pest.1996.0064

Park JH, Jeon YJ, Lee CH, Chung N, Lee HS (2017) Insecticidal toxicities of carvacrol and thymol derived from Thymus vulgaris Lin. against Pochazia shantungensis Chou \& Lu., newly recorded pest. Sci Rep-UK 7:40902. https://doi.org/10.1038/srep40902
Pavela R, Benelli G (2016) Essential oils as ecofriendly biopesticides? Challenges and constraints. Trends Plant Sci 21:1000-1007. https://doi.org/10.1016/j.tplants.2016.10.005

Pavela R, Maggi F, Iannarelli R, Benelli G (2019) Plant extracts for developing mosquito larvicides: From laboratory to the field, with insights on the modes of action. Acta Trop 193:236-271. https://doi.org/10.1016/j.actatropica.2019.01.019

Pavela R (2014) Insecticidal properties of Pimpinella anisum essential oils against the Culex quinquefasciatus and the nontarget organism Daphnia magna. J Asia-Pac Entomol 17:287293. https://doi.org/10.1016/j.aspen.2014.02.001

Pellegrini MC, Alonso-Salces RM, Umpierrez ML, Rossini C, Fuselli SR (2017) Chemical composition, antimicrobial activity, and mode of action of essential oils against Paenibacillus larvae, etiological agent of american foulbrood on Apis mellifera. Chem Biodivers 14:e1600382. https://doi. org/10.1002/cbdv.201600382

Sharifi-Rad J, Sureda A, Tenore GC, Daglia M, Sharifi-Rad M, Valussi M, Tundis R, Sharifi-Rad M, Loizzo M, Ademiluyi A, Sharifi-Rad R, Ayatollahi S, Iriti M (2017) Biological activities of essential oils: from Plant chemoecology to traditional healing systems. Molecules 22(1):70. https://doi.org/10.3390/ molecules 22010070

Sial MU, Zhao ZZ, Zhang L, Zhang YN, Mao LG, Jiang HY (2018) Evaluation of Insecticides induced hormesis on the demographic parameters of Myzus persicae and expression changes of metabolic resistance detoxification genes. Sci Rep-UK 8:16601. https://doi.org/10.1038/s41598-018-35076-1

Sial MU (2019) Resistant mechanisms to neonicotinoids and the detection of R81T mutation with LAMP in Myzus persicae. Dissertation, Chinese Academy of Agricultural Sciences

Singh RK, Dhiman RC, Mittal PK (2006) Mosquito larvicidal properties of Momordica charantia Linn (Family: Cucurbitaceae). J Vector Dis 43:88-91. https://doi.org/10.1111/j. 1526-4610.2009.01498.x

Tang QL, Xiang M, Hu HM, An CJ, Gao XW (2015) Evaluation of sublethal effects of sulfoxaflor on the green peach aphid (Hemiptera: Aphididae) using life table parameters. J Econ Entomol 108:2720-2728. https://doi.org/10.1093/jee/tov221

Walgenbach JF, Schoof SC (2011) Pepper chemigation study, 2010. Arthropod Manag Tests 36:E58. https://doi.org/10.4182/ amt.2011.E58

Wang YX, Shen Z (2002) Selective toxicity of four insecticides on green peach aphid (Homoptera: Aphididae) and predator multicolored Asian ladybird (Coleoptera: Coccinellidae) and the coordination evaluation of biological \& chemical control to insect pest. Chinese Journal of Pesticide Science 1:34-38

Xiao Y, Wu K (2019) Recent progress on the interaction between insects and Bacillus thuringiensis crops. Philos Trans R Soc Lond B Biol Sci 374:20180316. https://doi.org/10.1098/rstb.2018.0316

Xie YJ, Huang QQ, Rao YQ, Hong L, Zhang DY (2019) Efficacy of Origanum vulgare essential oil and carvacrol against the housefly, Musca domestica L. (Diptera: Muscidae). Environ Sci Pollut Res 26:23824-23831. https://doi.org/10.1007/s11356019-05671-4

Xie YJ, Wang K, Huang QY, Lei CL (2014) Evaluation toxicity of monoterpenes to subterranean termite, Reticulitermes chinensis Snyder. Ind Crop Prod 53:163-166. https://doi.org/10.1016/j.indcrop. 2013.12.021

Zeng XY, He YQ, Wu JX, Tang YM, Gu JT, Ding W, Zhang YQ (2016) Sublethal effects of cyantraniliprole and imidacloprid on feeding behavior and life table parameters of Myzus persicae (Hemiptera: Aphididae). J Econ Entomol 109:1595-1602. https:// doi.org/10.1093/jee/tow104

Zhang ZL, Xie YJ, Hu X, Shi HA, Wei M, Lin ZF (2018) Antifungal activity of monoterpenes against Botryosphaeria dothidea. 
Nat Prod Commun 13:1721-1724. https://doi.org/10.1177/ $1934578 \times 1801301234$

Zhang ZL, Xie YJ, Wang Y, Lin ZF, Wang LH, Li GY (2017) Toxicities of monoterpenes against housefly, Musca domestica L. (Diptera: Muscidae). Environ Sci Pollut Res 24:2470824713. https://doi.org/10.1007/s11356-017-0219-4

Zhang ZL, Yang T, Mi N, Wang Y, Li GY, Wang LH, Xie YJ (2016a) Antifungal activity of monoterpenes against wood white-rot fungi. Int Biodeter Biodegr 106:157-160. https://doi. org/10.1016/j.ibiod.2015.10.018
Zhang ZL, Yang T, Zhang YK, Wang LH, Xie YJ (2016b) Fumigant toxicity of monoterpenes against fruitfly, Drosophila melanogaster. Ind Crop Prod 81:147-151. https://doi. org/10.1016/j.indcrop.2015.11.076

Zhou LJ, Zhang ZL, Wei M, Xie YJ, He S, Shi HA, Lin ZF (2019) Evaluation of the antifungal activity of individual and combined monoterpenes against Rhizopus stolonifer and Absidia coerulea. Environ Sci Pollut Res 26:7804-7809. https://doi.org/10.1007/ s11356-019-04278-z 